\title{
A Study of the Management of University Research Funds from the Perspective of Internal Control
}

\author{
XIA Jing, DU Guoliang \\ Finance Department, Wuhan University of Textile, \\ Wuhan, P.R. China, 430200 \\ E-mail: callidora2015@163.com; 95255286@qq.com
}

Keywords: University; research funds; internal control

\begin{abstract}
With the rapid increase of university research funds, effective management of university research funds becomes an urgent problem to be solved. In view of the indefinite control objective, incomplete system as well as the lack of supervision in the existing internal control of Chinese university research funds, this article proposes that in terms of the internal control of university research funds in China, we should establish definite objective, improve internal control system and implement the internal control audit.
\end{abstract}

\section{Introduction}

As the organization of training high-level professional personnel, making scientific innovation and also inheriting human knowledge, university has formidable superiority in scientific study. Also through the scientific study, university can realize the goal of enhancing teaching quality and developing discipline construction and then strengthen social bond and comprehensive strength. Considering the important role of scientific study in university development, every country attaches great significance to greatly supporting university in scientific research. As the economy of our country develops the research funds that our country allocates to universities increases dramatically. Meanwhile, universities also receive much support from enterprises as well as social organizations. In a word, these research funds play an important role in the scientific research of Chinese universities as well as the scientific innovation in China. [1] However, in recent years, more and more problems are exposed in the management of university research funds, which indicates that there is something wrong with the existing research funds management. Internal control refers to the series of control activities performed by the stakeholder and aimed at reasonably guaranteeing the realization of the basic goal of the organization. Internal control can not only reasonably guarantee organization asset security, accounting information reliability, control action legitimacy but also raise the organizing and management level and operating efficiency of the organization and thus internal control has become an important part of modern university system. [2] Hence, it is necessary to probe into the issues relevant to the internal control of the university research funds so as to to raise the management level of university research funds.

\section{The existing problems with the internal control of university research funds}

Internal control is the important component of modern university system and our universities have set up necessary and appropriate internal control system in their development. The internal control system gives a full play to regulating university accounting information authenticity and reliability, the normal proceeding of teaching and research, asset security as well as the realization of university development goal. However, as universities gradually become a significant part of our national innovation system and national university research funds increase sharply and meanwhile various research funds that university receives show a sustainable and rapid increasing 
trend, many management problems are exposed. Among these issues, weak internal control of university research funds is the most prominent one and can hardly meet the requirements of university research funds in the new situation. [3] The problems of the internal control of university research funds management are mainly displayed in the following respects.

\section{The objective of university internal control is not clear.}

University research funds management has its own characteristic. On one hand, scientific and technological advance needs innovative research work and also needs to give researchers full free power in using the funds so as to provide good material condition for achieving scheduled research goal; On the other hand, scientific study is high-risk exploratory activity and will definitely suffer setbacks and defeats and also research funds are very likely to be in vain. This characteristic means research funds management should not only be legitimate and achieve academic freedom and funds standardization, but also avoid tyranny in research funds management that might make researchers unable to carry out effective scientific study. [4] This characteristic of using research funds causes the goal of the Chinese university internal control to be unclear. In the early time, research funds principal is given much power and the research funds management policy is too loose. The problems that the scientific research project principal does not use the research funds reasonably according to the budget and that the big-ticket project lack rationality and that various funds reimbursement are not consistent with the actual expenditure and so on are very prominent. In the near future, with our nation attaching importance to the standardization and rationality of university research funds and also media exposure of numerous illegal research spending activities, many universities issue various rules to strengthen the management of research funds. However, many rules are only made from the perspective of strengthening financial management, but neglect the characteristics of scientific research as well as the particularity in using research funds, which causes difficulty in using research funds and seriously restricts the normal proceeding of scientific study. [5]The internal control goal of university research funds is related to legitimacy and efficiency of financial management. However, previous internal control ignores the importance of this goal, causing the existing research funds control to go to two extremes.

The internal control system in university is imperfect.

Internal control is a kind of control activity that an organization performs to adapt to management demand. This control activity can ensure the realization of organization goal, protect asset security and accounting information reliability and authenticity and also improve the efficiency of operative activities. The internal control of university research funds involves funds appropriation, administrative unit, the project principal, funds reimbursement principal, the funds supervisor and so on and also involves highly liquid assets (e.g. cash ) and large-scale fixed assets (e.g. instruments). This means the internal control of university research funds not only needs to coordinate with many other departments, but also needs scientific and normal internal control system to regulate the behavior of relevant parties. Effective internal control system of research funds should be established based on the state laws and regulation as well as the internal control principle, which clearly stipulates the research funds counterparts' responsibilities and rights and benefits and tries to make different posts act with each other in using research funds so as to use the least internal control coast to achieve benefit maximization of internal control. The rapid growth of university research funds in our country causes the existing management department to be ill-equipped, which is displayed in the imperfect internal control system. The first is the unsatisfactory internal control environment of university research funds. [6] The university management structure in our country is in the process of improvement and related university system does not suit our university development. Specifically in the management of university research funds, there is no funds application, funds use, and funds supervision system and also the research funds manager, project principal as well as the scientific researchers have weak internal control idea of university research funds and lack knowledge about the importance of internal control of university research funds. The second is the lack of risk awareness in university research funds management. Risk management, including risk identification, risk assessment, risk control and risk 
management effect evaluation and other procedures, is an important part of internal control. In the management process of our university research funds, we lack basic management content of research funds risk. Not only do we have no corresponding management department to evaluate the risk in the research program, but also we have no specialized technical personnel to analyze the risk of the research program. Nor do we have scientific methods to make quantitative analysis of the risk of various research programs. The third is that we haven't established scientific and rational internal control evaluation standard of university research funds. The benefit of research funds not only concerns the normal proceeding of the research program but also concerns the realization of the scheduled research goal of the university as well as the national innovative activities. Thus, every country attaches significance to the research funds results evaluation. Since we lack related professionals and also the results evaluation method is backward, the internal control evaluation in our university research funds mainly stresses the rationality and authenticity of funds disbursement and pay less attention to the benefit of using research funds.

\section{The internal control supervising mechanism of university research funds is not perfect.}

The perfect internal control supervising mechanism is an essential part of the modern internal control system. In the various internal control supervising mechanisms, audit is quite an effective one. However, with university research funds increasing rapidly, the audit activities in our universities have not adapted to the progress of this situation, which is mainly displayed in the following aspects. First, we lack high-quality auditors. The existing university audit is mainly concentrated on the financial revenue and expenditure audit, the cadre economic accountability audit and project audit and lacks the experience of performance audit. Second, the specialized relation between the research funds disbursement and research program increases the audit difficulty. The research program often involves quite deep expertise, which greatly limits the prior commitment of auditors and also hinders the communication between the auditor and scientific researchers. [7] Our universities have not established such audit pattern to adapt to this situation. Third, the independence of the existing university audit activities is weak and can hardly make accurate audit conclusion about research funds.

\section{The internal control system arrangement of university research funds}

The university as well as the control department needs to consider the application, use as well as supervision of university research funds and establish internal control system fit for the highly effective use of university research funds.

First, we should set internal control objective of university research funds. The internal control objective is the basis for deciding the direction of internal control and is also the expected results of organizing internal control activities. The internal control objective of university research funds can be defined as legitimacy, efficiency and reliability of information. The legitimacy means that the use of university research funds must first conform to the relevant national laws and regulations and strictly increase and decrease, transfer and balance the research funds according to the research funds management method and stipulation of related ministries.

The efficiency means that the application of research funds should be based on scientific and reasonable plan and proper use should be made of the funds through effective way and also scientific method of financial management should be adopted in planning research funds use so as to ensure the normal proceeding of scientific research and realize the scheduled scientific goal.

The information reliability means that we should not only disclose the use of funds strictly according to the accounting system but also accurately reflect the existing scientific study situation so as to make the information provided by funds use and scientific study process and result real and reliable.

Second, we need to improve the internal control system of university research funds. According to the existing internal control frame, the internal control mainly includes the control environment, the risk assessment, control activity, information and communication and supervision. Considering the fact that research program must comply with relevant laws and regulations and 
raise the fund efficiency as well control the risk, the internal control system construction of the university research funds should focus on the control environment, the risk assessment as well as the controlling process the university research funds.

The internal control environment is the foundation of other internal control factors and decides internal control tone of the university research funds and also directly influences the understanding and attitude of the research funds manager, the research project principal and the researchers to the internal control. In universities, we should firstly build internal control environment appropriate for scientific research activities. In addition, in the internal control environment construction process of university research funds, we should pay close attention to the competency of relevant personnel and establish appraisal system to guarantee normal proceeding of internal control activities.

The risk assessment will provide the risk type facing the organization and also makes qualitative or qualitative assessment. In the risk assessment of university research funds, we can take advantage of the university expert resources and also hire a certain amount of specialized experts in risk assessment and provide directive suggestions for scientific research program application, budget drafting, funds use, large-scale disbursement and necessity and rationality of purchasing special equipment and so on.

Control activity refers to the risk-controlling policies and procedures adopted by the organization which are aimed at guaranteeing implementation of internal control. Considering the fact that scientific activities involve strong expertise and the research funds use includes budget, appropriation, disbursement and balance, we could design the control content of each link according to the use flow of the research funds.

Third, we should strengthen the internal control audit of university research funds. Every system has flaw and so does the internal control. Thus, we need to identify the internal control validity. The internal control audit is the process of identifying, assessing internal control validity and it analyzes in detail the flaw and the reason for flaw in university internal control design and operating process and provide improvement suggestions.

First, we should establish standard and scientific and rational power and responsibility structure in university research funds to make the university scientific research program principal, scientific researchers and the control department have rights as well as responsibilities in the research funds management.

Next, we need to raise the internal control awareness of relevant personnel of university research funds and form strong internal control atmosphere in the university research funds management to make the internal control become the conscientious behavior of relevant personnel.

Finally, we should establish the auditing system that meets the needs of the internal control of university research funds. In view of the research program characteristics and research funds operating law, universities should establish internal control according to the audit system assisted by budget implementation and large -scale expenditure as well as scientific research performance audit on the basis of establishing audit team needed by the scientific research audit.

\section{Conclusion}

The university internal control system serves the long-term development of university. In the process of guaranteeing university teaching, scientific researches as well as making society develop in a normal way; this internal system will protect the asset security, accounting information accuracy and will also effectively reduce various risks in university operation. Based on this, it is necessary to establish sound internal control system in our university research funds so as to make the use of university research funds normal and legal and provide the institutional guarantee for arousing the research enthusiasm of the researchers and creating good scientific research atmosphere in universities. 


\section{References}

[1] Ministry of Education, Ministry of Finance. Advice of Ministry of Education and Ministry of Finance about strengthening research funds management of central department universities [S].2012.

[2] Advice of Ministry of Education about further improving university project management [S].2012.

[3] Advice of Ministry of Education about further standardizing university scientific research [S].2012.

[4] Ministry of Finance Accountant Department. Seminar about the internal control standard of administrative institutions [M]. Beijing: Economic science publishing house, 2013.

[5] Gao Qingfeng. The internal control system construction issue in universities and its countermeasures [J] Friends of accounting, 2013(2): 126-128.

[6] LanYing. A study of improving the university research funds management [J]. Friends of accounting 2012(2): 114-116.

[7] Qi Xingqiang. Problems of university research funds management and its countermeasures [J]. Friends of accounting, 2013(28): 108-110. 